\title{
LOS “MATRIMONIOS DE CONVENIENCIA” EN ESPAÑA: INDICIOS.
}

\section{THE "MARRIAGE OF CONVENIENCE" IN SPAIN: SIGNS}

\author{
Alfonso Ortega \\ Universidad Miguel Hernández, Elche. España/Spain \\ alfonso.ortega@umh.es
}

Recibido/Received: 11/08/2014

Modificado/Modified: 22/08/2014

Aceptado/Accepted: 30/09/2014

\section{RESUMEN}

Este artículo es un análisis del problema de los denominados "matrimonios de conveniencia", fenómeno muy común en los países sometidos a fuerte inmigración y que comienza a tener bastante importancia en España. De esta forma, en el presente trabajo trataremos de, tras concretar qué se entiende por "matrimonio de conveniencia", analizar la verdadera razón de ser de esta práctica, para así, poder detenernos en el examen de aquellos indicios que permitan identificar un "matrimonio de conveniencia".

\section{PALABRAS CLAVE}

Matrimonio, conveniencia, inmigración, nacionalidad española.

\section{SUMARIO}

1. Concepto de "matrimonio de conveniencia". 2. Indicios de matrimonio de conveniencia. 3. Reflexiones finales. Bibliografía.

\section{ABSTRACT}

This paper is an analysis of the problem of so-called "marriages of convenience" very common phenomenon in countries undergoing strong immigration and starting to be quite important in Spain. Thus, in this paper try after forming what is meant by "marriage of convenience", analyze the real reason for this practice, thus, be able to stop in examining those indications which identify a "marriage of convenience".

\section{KEYWORDS}

Marriage, convenience, immigration, Spanish nationality.

\section{CONTENTS}

1. Concept of "marriage of convenience". 2. Signs of marriage of convenience. 3. Final thoughts. References 


\section{CONCEPTO DE "MATRIMONIO DE CONVENIENCIA"}

Si queremos dar un concepto de "matrimonio de conveniencia" debemos acudir a la Resolución del Consejo de la Unión Europea, de 4 de Diciembre de 1997, sobre las medidas que deberán adoptarse en materia de lucha contra matrimonios fraudulentos (DOCE C 382, de 16 de Diciembre de 1997). Con arreglo a la presente Resolución se establece que se entenderá por "matrimonio fraudulento", el matrimonio de un nacional de un Estado miembro o de un nacional de un tercer país que resida regularmente en un Estado miembro con un nacional de un tercer país, con el fin exclusivo de eludir las normas relativas a la entrada y la residencia de nacionales de terceros países y obtener, para el nacional de un tercer país, un permiso de residencia o una autorización de residencia en un Estado miembro. Este concepto de "matrimonio de conveniencia" ha sido seguido por la Fiscalía General del Estado, que, mediante la Circular 1/2002, define los "matrimonios de conveniencia" como "aquellos matrimonios celebrados con la única finalidad de regularizar la situación en España de uno de los contrayentes, mediante el matrimonio con español o con quien ya se encuentra legalmente en el país”.

Se señalan como factores que pueden permitir que se presuma que un matrimonio es fraudulento, en particular, los siguientes:

a) El no mantenimiento de la vida en común;

b) La ausencia de una contribución adecuada a las responsabilidades derivadas del matrimonio;

c) El hecho de que los cónyuges no se hayan conocido antes del matrimonio;

d) El hecho de que los cónyuges se equivoquen sobre sus respectivos datos personales y profesionales -nombre, dirección, nacionalidad, trabajo-, sobre las circunstancias en que se conocieron o sobre otros datos de carácter personal relacionados con ellos;

e) El hecho de que los cónyuges no hablen una lengua comprensible para ambos;

f) El hecho de que se haya entregado una cantidad monetaria para que se celebre el matrimonio -a excepción de las cantidades entregadas en concepto de dote, en el caso de los nacionales de terceros países en los cuales la aportación de una dote sea práctica normal-; o,

g) El hecho de que el historial de uno de los cónyuges revele matrimonios fraudulentos anteriores o irregularidades en materia de residencia.

Con el fin de luchar contra el fraude en esta materia, y erradicar los "matrimonios fraudulentos", en la misma línea de principios, la Dirección General de los Registros y del Notariado (en adelante, DGRN), hasta la fecha ha dictado dos Instrucciones de interés: a) una, de 9 de enero de 1995, sobre el expediente previo al matrimonio cuando uno de los contrayentes está domiciliado en el extranjero - BOE núm. 21, de 25 de enero de 1995-; y, otra, de 31 de enero de 2006, sobre los matrimonios de complacencia - BOE núm. 41, de 17 de febrero de 2006-.

De esta forma, la DGRN da a conocer una serie de orientaciones y reglas con el fin de evitar la proliferación de "matrimonios de conveniencia": a los Encargados de los Registros Civiles españoles se les indica, por ejemplo, que "debe considerarse y presumirse que existe auténtico consentimiento matrimonial", cuando un contrayente conoce "los datos personales y/o familiares básicos del otro". Eso sí, teniendo en cuenta ciertas reglas, como que el desconocimiento "debe ser claro, evidente y flagrante", que no es preciso "descender a los detalles más concretos posibles" y que no puede fijarse una "lista cerrada" de datos básicos de obligado conocimiento. Además, para acreditar la existencia de auténticas y verdaderas relaciones entre los contrayentes deben tenerse en cuenta seis reglas, como tiempo y tipo de 
relaciones de convivencia, idioma común, matrimonios simulados anteriores y prueba indubitable de entrega de una cantidad económica.

El verdadero objetivo de estos matrimonios de complacencia es obtener determinados beneficios en materia de Derecho de la nacionalidad y de la extranjería: por un lado, adquirir de modo acelerado la nacionalidad española, en la medida en que el cónyuge del ciudadano español goza de una posición privilegiada para la adquisición de la nacionalidad española (artículo 22.2 de nuestro $\mathrm{CC}$ ): basta un año de residencia en España por parte del sujeto extranjero (artículo 22.2 del CC), siempre que sea una residencia "legal, continuada e inmediatamente anterior a la Petición" (artículo 22.3 del CC); y, por otro lado, lograr una autorización de residencia en España, ya que el extranjero que ostenta la nacionalidad de un tercer Estado no miembro de la UE ni del EEE y que sea cónyuge o pareja de hecho de un ciudadano español, goza del derecho a residir en España.

En definitiva, los llamados "matrimonios de complacencia" se celebran, frecuentemente, a cambio de un precio: un sujeto -frecuentemente, aunque no siempre, un ciudadano extranjero-, paga una cantidad a otro sujeto -normalmente, aunque no siempre, un ciudadano español-, para que éste último acceda a contraer matrimonio con él, con el acuerdo, expreso o tácito, de que nunca habrá "convivencia matrimonial auténtica" ni "voluntad de fundar y formar una familia", y de que, pasado un año u otro plazo convenido, se instará la separación judicial o el divorcio.

\section{INDICIOS DE MATRIMONIO DE CONVENIENCIA}

Podríamos señalar como indicios para la calificación de un matrimonio como "de conveniencia" los siguientes": 1) La imposibilidad de comunicación a través de una lengua común, 2) el desconocimiento de las circunstancias personales y familiares del otro contrayente, 3) la notable diferencia de edad entre los contrayentes, 4) la situación de irregularidad del contrayente extranjero, 5) las discrepancias entre las declaraciones de los contrayentes, 6) y/o las confesiones de los contrayentes.

Veamos cada uno de ellos, a través de diferentes Resoluciones de la DGRN (2010-2013):

\section{1) Imposibilidad de comunicación a través de una lengua común}

\section{2) Desconocimiento de las circunstancias personales y familiares del otro contrayente}

a) Resolución de la DGRN 21 de enero de 2010

Un hombre de nacionalidad marroquí y una mujer de nacionalidad española, solicitan autorización para contraer matrimonio civil. Se acompaña la documentación pertinente y además comparece un testigo, el cual afirma que dicho matrimonio no incurre en ilegalidad alguna. Posteriormente se celebran las entrevistas en audiencia privada con los contrayentes y el Ministerio Fiscal se opone a la autorización del matrimonio. Finalmente se deniega la autorización al faltar el consentimiento matrimonial.

De las entrevistas celebradas en audiencia privada se deduce que, [los contrayentes no tienen una lengua común, lo que da lugar a importantes problemas de comunicación. Además el interesado tiene un importante desconocimiento de los datos personales y demás circunstancias familiares de ella los contrayentes no coinciden sobre la fecha en la que se conocieron, él dice que en el verano de 2007 y ella que en enero de 2006, además ella desconoce la fecha exacta de nacimiento de él]. 
b) Resolución de la DGRN de 21 de julio de 2011

Una mujer de doble nacionalidad, española y colombiana junto a un hombre de nacionalidad japonesa, solicitan ante el consulado español en Tokio una autorización para contraer matrimonio civil. Sin haber testigo alguno que acredite la veracidad de la relación se procede a celebrar las entrevistas en audiencia privada. Previo informe desfavorable por parte del Ministerio Fiscal, la encargada del Registro deniega la autorización por falta de consentimiento matrimonial.

De las entrevistas celebradas en audiencia privada se concluye que, [la pareja no tiene una lengua común, ya que ambos han reconocido que solo hablan la lengua de sus países de origen respectivamente, español ella y japonés él. Además existe un gran desconocimiento mutuo sobre importantes circunstancias personales, el interesado desconoce el origen colombiano de ella, así como sus aficiones, las cuales según él son el ordenador y las discotecas mientras que ella declara que le gusta ver tenis en televisión. Así mismo ella desconoce sobre él, los hijos que tiene y qué estudios posee, además al ser preguntada por las aficiones de él, ella asegura que le gusta el golf mientras que él dice que le gustan los billares japoneses].

c) Resolución de la DGRN de 21 de septiembre de 2011

Una mujer de nacionalidad española y un hombre de nacionalidad nigeriana, presentan escrito ante el Registro Civil de Murcia, para iniciar expediente en solicitud de autorización para contraer matrimonio civil. Ratificados los solicitantes, se procede a celebrar las entrevistas en audiencia privada. El Ministerio Fiscal se opone a la autorización del matrimonio y el encargado del Registro Civil, resuelve mediante auto denegando la autorización del enlace.

De las audiencias, se puede observar que [ambos contrayentes no comparten una lengua común, pues ambos declaran que ella solo habla español y que está estudiando inglés, mientras que él apenas se expresa en español. Por otro lado, es patente el desconocimiento mutuo de circunstancias personales importantes, como que él desconoce la fecha y el lugar de nacimiento de ella, no está seguro de su primer apellido y desconoce el segundo. Por parte de ella, no expresa correctamente ni el nombre ni el apellido de su pareja, además desconoce el nombre del padre y los hermanos de él].

d) Resolución de la DGRN de 9 de enero de 2012

Un hombre de nacionalidad española, presenta ante el Registro Civil de Córdoba de dónde es vecino, una solicitud para que se le expedite un certificado de capacidad para poder contraer matrimonio en Marruecos con una mujer nacional de dicho país. Comparecen como testigos, la hermana y la prima de la interesada alegando que no existe impedimento legal alguno para que se celebre el enlace. El interesado fue oído en audiencia privada y la interesada fue oída reservadamente en el Registro Civil Consular de Rabat con asistencia de intérprete-traductor.

Tras el informe desfavorable del Ministerio Fiscal, el encargado del Registro Civil de Córdoba deniega la autorización. De las audiencias celebradas con los contrayentes se desprende [la inexistencia de una lengua común que posibilite la comunicación, ella misma confiesa que para comunicarse con él siempre lo hacen a través de la hermana de ella. Además de advierte un acusado desconocimiento recíproco de datos personales básicos, como los nombres de los hijos del otro, las fechas de nacimiento, etc.] 
e) Resolución de la DGRN de 8 de julio de 2012

Un individuo de nacionalidad maliense, presenta ante el Consulado de España en Bamako (Mali) la hoja declaratoria de datos para la inscripción de su matrimonio celebrado en Mali con una señora de nacionalidad española. Se celebran las audiencias preceptivas. El Ministerio Fiscal emite un informe desfavorable y el encargado del Registro deniega la inscripción del matrimonio.

En cuanto a las respuestas ofrecidas por los contrayentes en las audiencias se observa un desconocimiento casi total de la otra persona, discrepan en aficiones, deportes practicados, tratamientos médicos de ella, salario de él, desconocen las direcciones y teléfonos de cada uno. Además él ignora completamente la lengua española, por lo que no existe lengua común entre los interesados.

f) Resolución de la DGRN de 18 de octubre de 2012

Mediante escrito presentado ante el Registro Civil, un señor nacido en España, de nacionalidad española y una mujer nacida en Marruecos, de nacionalidad marroquí, solicitaba certificado de capacidad para contraer matrimonio civil en Marruecos. El promotor ratifica la solicitud y como testigo es oída la madre de éste. Días después ratifica la interesada en el Registro Civil Consular de Rabat y es oída en audiencia reservada con asistencia de intérprete-traductor. El Ministerio Fiscal se opone al enlace y el encargado del Registro resuelve mediante auto denegando la capacidad matrimonial.

De ambas audiencias se desprende, [que ambos contrayentes no comparten una lengua común, queda registrado que ella debe realizar la entrevista con la asistencia de un intérprete, él dice que se comunican mediante frases cortas en árabe, español y francés y ella que mediante la ayuda de su tía y chapurreando. Además existe desconocimiento de circunstancias personales, ella no sabe que él convive con sus padres y con sus dos hermanos, a los que sitúa fuera de la casa].

\section{3) Notable diferencia de edad entre los contrayentes}

a) Resolución de la DGRN de 13 de diciembre de 2013

Mediante escrito presentado ante el Registro Civil, un hombre de nacionalidad ecuatoriana y una mujer de nacionalidad española, iniciaban expediente en solicitud de autorización para contraer matrimonio civil. Se celebran las entrevistas en audiencias reservadas. El Ministerio Fiscal informa desfavorablemente y la encargada del Registro Civil no autoriza la celebración del matrimonio.

De las audiencias celebradas observamos que [existe desconocimiento en cuanto a ciertas circunstancias personales del otro contrayente, ella dice que su pareja tiene 9 hermanos, mientras que él dice que 8. Ella dice que su pareja la ayuda económicamente y él dice que no trabaja. Además y sin que sea determinante por sí solo, existe una notable diferencia de edad entre los contrayentes de aproximadamente 18 años].

b) Resolución de la DGRN de 1 de septiembre de 2011

Una mujer de nacionalidad dominicana, solicitó en el Registro Civil español la inscripción de su matrimonio con un hombre de nacionalidad española, celebrado en la República Dominicana según la ley local de dicho país.

Se celebra trámite de audiencia reservada por separado con ambos solicitantes. El Registro Civil dictó auto denegando la inscripción solicitada por falta de verdadero consentimiento matrimonial. 
De las audiencias celebradas se observan inconsistencias y contradicciones de las que se desprende un mutuo desconocimiento de circunstancias personales importantes. Él no conoce el nombre de su suegro ni puede nombrar el nombre de ninguno de sus cinco cuñados.

Además cabe señalar la importante diferencia de edad entre los contrayentes, 27 años tiene él más que ella.

c) Resolución de la DGRN de 10 de diciembre de 2013

Un hombre de nacionalidad colombiana, junto a una mujer de nacionalidad española, presentan ante el Registro Civil un escrito por el cual solicitan autorización para contraer matrimonio civil. Comparecen dos testigos que afirman que no existe impedimento legal para que el enlace sea celebrado. Se llevan a cabo las entrevistas privadas con los interesados. El Ministerio Fiscal se posiciona desfavorablemente y la encargada del Registro Civil no autoriza la celebración del matrimonio.

De las entrevistas se concluye que, [los contrayentes ignoran datos personales y familiares básicos, por ejemplo, ella desconoce el número de teléfono de él y a pesar de que viven juntos, ignora el número de hermanos de su pareja. Además se observa una notable diferencia de edad de 12 años entre los contrayentes].

d) Resolución de la DGRN de 11 de diciembre de 2013

Mediante escrito presentado ante el Registro Civil, una señora de nacionalidad española y un señor de nacionalidad pakistaní, iniciaban expediente de autorización para contraer matrimonio civil. Celebradas las entrevistas en audiencia privada, el Ministerio Fiscal se opone a la autorización y el encargado del Registro deniega la autorización.

De las entrevistas realizadas se desprende que [existe desconocimiento mutuo respecto de datos de carácter personal que deberían ser conocidos, él declara que ella fuma, a lo que ella responde que no, también discrepan sobre el último regalo que recibieron de su pareja y sobre la fecha y el lugar en el cual él le propuso matrimonio a ella. La diferencia de edad es un factor más a destacar, aunque por sí mismo no sea determinante, existiendo 15 años de diferencia entre los contrayentes].

e) Resolución de la DGRN de 13 de diciembre de 2013

Un hombre nacido en España, de nacionalidad española y una mujer nacida en Brasil, de nacionalidad brasileña solicitan ante el Registro Civil una autorización para contraer matrimonio civil. Comparecen dos testigos manifestando que el matrimonio proyectado no incurre en prohibición legal alguna. Se celebran las entrevistas en audiencia reservada y el Ministerio Fiscal informa desfavorablemente. Finalmente el encargado del Registro no autoriza la celebración del enlace.

De las audiencias se desprenden [hechos objetivos de los que cabe deducir que el matrimonio no persigue los fines propios de dicha institución, existen contradicciones y desconocimiento de datos básicos personales y familiares, como que declaran vivir juntos, pero cada uno sitúa el domicilio en una población distinta. La interesada no sabe con quién vive la hija de él, además discrepan sobre quién asistirá al enlace y ella no conoce los ingresos de su pareja].

No se puede ignorar, aunque por sí sola no sea determinante la importante diferencia de edad entre los interesados, 24 años.

f) Resolución de la DGRN de 10 de octubre de 2012

Mediante escrito civil presentado en el Registro Civil de Algeciras, un hombre de nacionalidad española y una mujer de nacionalidad paraguaya, inician expediente de solicitud 
de autorización para contraer matrimonio civil. Ratificados los interesados, comparece un testigo elegido por el instructor entre los propuestos por los solicitantes, dicho testigo declara que tiene el pleno convencimiento de que el matrimonio no incurre en prohibición legal alguna. Se celebran las entrevistas en audiencia reservada. El Ministerio Fiscal informa de manera desfavorable sobre las entrevistas y el encargado del Registro resuelve dictando auto que deniega la autorización del matrimonio proyectado.

De las audiencias reservadas se desprende, [un desconocimiento mutuo de información personal, el interesado desconoce el nombre completo de la interesada, también desconoce la fecha y el lugar de nacimiento de la interesada, desconocen, además, el número de hermanos de ambos y circunstancias de los mismos, a ello hay que sumar la gran diferencia de edad entre ambos, 52 años].

g) Resolución de la DGRN de 29 de octubre de 2012

Un hombre de nacionalidad española junto a una mujer de nacionalidad dominicana, presentan ante el Registro Civil un escrito para solicitar autorización para contraer matrimonio civil. Se celebran las audiencias reservadas. El Ministerio fiscal informa desfavorablemente la autorización del matrimonio. La Juez encargada del Registro Civil no autoriza la celebración del matrimonio.

De las audiencias se puede deducir [la existencia de desconocimiento de los datos personales de los interesados, el compareciente desconoce el nombre y apellidos de los padres de su pareja, así como en el lugar en el que residen y sus profesiones. Tampoco sabe precisar el número de hermanos que tiene la interesada, ni sus nombres. Además y sin que sea determinante la diferencia de edad de 33 años entre los interesados].

h) Resolución de la DGRN de 29 de octubre de 2012

Una mujer de nacionalidad colombiana, ante el Registro Civil consular de Bogotá, presenta declaración de datos para la inscripción de su matrimonio con un hombre de nacionalidad colombiana y española, esta última adquirida por residencia. Los interesados realizan las entrevistas en audiencia reservada y el Ministerio Fiscal se opone a la inscripción del matrimonio. El encargado del Registro Civil Consular estimando la consideración del Ministerio Fiscal y las alegaciones de los contrayentes, resuelve dictando auto denegatorio.

De las audiencias se desprende que, [existen contradicciones y desconocimiento de información personal mutuo, no conocen las profesiones sus respectivos hermanos, no coinciden al indicar las profesiones de los suegros. Aunque no sea determinante, existe una notable diferencia de edad entre los contrayentes de 13 años].

\section{Situación de irregularidad del contrayente extranjero}

\section{Discrepancias entre las declaraciones de los contrayentes}

a) Resolución de la DGRN de 10 de diciembre de 2013

Se presenta ante el Registro Civil por parte de un hombre de nacionalidad española y una mujer nacida en Marruecos, de nacionalidad marroquí, un escrito mediante el cual solicitan autorización para contraer matrimonio civil. Comparecen dos testigos, los cuales declaran no conocer impedimento legal alguno para que no se celebre el enlace. Se celebran las entrevistas en audiencia reservada y posteriormente el Ministerio Fiscal se opone a dicha autorización. El encargado del Registro resuelve mediante auto denegando la autorización.

De las audiencias reservadas [se observan numerosas contradicciones entre las declaraciones de los contrayentes, discrepan en las profesiones de cada uno y además 
desconocen las fechas de nacimiento y el nombre completo del otro. Además y sin que sea determinante por sí solo, la interesada se encuentra en situación irregular en España].

b) Resolución de la DGRN de 12 de diciembre de 2013

Un hombre nacionalidad marroquí y una mujer de nacionalidad española, solicitan ante el Registro Civil una autorización para contraer matrimonio civil. Comparece un testigo a favor del matrimonio. Se celebran las entrevistas en audiencia reservada. El Ministerio Fiscal se opone a la autorización y el encargado del Registro resuelve denegando la autorización.

De las audiencias se desprende, [que existen discrepancias entre las declaraciones de los contrayentes, como el tiempo que lleva él en España y la forma en la que se conocieron, ella dice que por Internet y él dice que físicamente. Además y sin que sea concluyente el visado de residencia del interesado caducó, con lo que se encuentra en situación irregular en España].

c) Resolución de la DGRN de 2 de septiembre de 2013

Mediante escrito presentado ante el Registro Civil, un hombre de nacionalidad marroquí y una mujer de nacionalidad española, solicitan autorización para contraer matrimonio civil. Ratificados los interesados, comparecen dos testigos que manifiestan que no existe impedimento legal para que el enlace se celebre. Se llevan a cabo las entrevistas celebradas en audiencia reservada. El Ministerio Fiscal informa desfavorablemente y finalmente el encargado del Registro resuelve mediante auto denegando la autorización.

De las audiencias celebradas se desprenden hechos objetivos que hacen dudar de que dicho enlace persigue los fines adecuados, [el interesado declara que se encuentra en situación irregular en España y tiene pendiente una orden de expulsión (hay que tener muy en cuenta el informe de la policía de extranjería donde se pone de manifiesto hechos y situaciones indicadores de la situación de irregularidad del interesado), además existen contradicciones en las declaraciones de los contrayentes, respecto al domicilio en el que vivieron en un momento anterior al actual y en cuanto a la relación de la interesada con sus padres].

d) Resolución de la DGRN de dos de septiembre de 2013

Una mujer de nacionalidad española y un hombre nacido en Costa de Marfil, de nacionalidad marfileña, solicitan en el Registro Civil una autorización para contraer matrimonio civil. Después de ser ratificados los contrayentes y de haber comparecido los testigos se procede a celebrar las entrevistas en audiencia reservada. El Ministerio Fiscal informa de manera desfavorable. La solicitud se deniega por falta de los requisitos necesarios.

De las entrevistas cabe destacar, [las numerosas contradicciones observadas entre las respuestas de los interesados, no coinciden en el número de hermanos que el contrayente tiene, discrepan totalmente en la forma y tiempo en el que se conocieron. Además, aunque por sí solo no es determinante, el promotor se encuentra en situación irregular en España ya que carece de permiso de residencia].

e) Resolución de la DGRN de 7 de octubre de 2013

Un hombre de nacionalidad española junto a una mujer de nacionalidad rusa, presentan escrito ante el Registro Civil para poder contraer matrimonio civil, acompañando documentación pertinente. Ratificados los interesados, se procede a celebrar las entrevistas en audiencia reservada. Tras dichas entrevistas el Ministerio Fiscal informa 
desfavorablemente. El encargado del registro resuelve no autorizando la celebración del matrimonio.

De las audiencias se deduce que, [existen discrepancias entre las declaraciones de los interesados, no coinciden en cuándo decidieron contraer matrimonio, tampoco coinciden en dónde ni cuánto tiempo han estado viviendo juntos. Él declara que ella trabaja en una empresa propiedad de la hermana de ésta, mientras que ella dice que no trabaja. Además y sin que sea determinante, se debe tener en cuenta la situación de irregularidad de la interesada al carecer de permiso de residencia en España].

f) Resolución de la DGRN de 8 de septiembre de 2011

Mediante escrito presentado en el Registro Civil, un hombre de nacionalidad hindú y una mujer de nacionalidad holandesa, inician expediente en solicitud de autorización para contraer matrimonio civil. Oídos los interesados en audiencia privada, el Ministerio Fiscal se opone al matrimonio, aunque el juez encargado del Registro Civil autoriza el enlace. El Ministerio Fiscal interpone un recurso contra el auto del juez y finalmente la DGNR deniega la autorización para contraer matrimonio.

De las audiencias reservadas se extrae que, [los interesados discrepan en varias cosas, como en los estudios cursados por él, él dice que estudió hasta los 18 años y ella que cursó Formación Profesional. Además, según informe policial, él se encuentra en situación irregular en España y no ha efectuado ningún trámite al respecto].

\section{Confesiones de los contrayentes}

a) Resolución de la DGRN de 12 de diciembre de 2013

Un hombre de nacionalidad georgiana y una mujer de nacionalidad española, inician mediante escrito ante el Registro Civil un expediente en solicitud de autorización para contraer matrimonio civil. El mismo día se ratifican los interesados, es oído el testigo aportado y se celebran las audiencias reservadas. El Ministerio Fiscal informa desfavorablemente respecto de dicho matrimonio y el encargado del Registro resuelve denegando la autorización.

En las audiencias reservadas, [el hombre de nacionalidad georgiana, el cual se encuentra en situación irregular desde hace 10 años en España, declara que "en primer lugar quiere casarse para obtener los papeles [...]" añadiendo la mujer, "que sabe que casándose con ella tendrá más facilidad para obtener la nacionalidad española"].

b) Resolución de la DGRN de 24 de octubre de 2012

Mediante escrito presentado ante el Registro Civil, un hombre de nacionalidad española y una mujer de nacionalidad brasileña, inician expediente de solicitud de autorización para contraer matrimonio civil. Oídos dos testigos, que declaran que el matrimonio no incurre en prohibición legal alguna, se procede a celebrar las entrevistas privadas con los interesados. El Ministerio Fiscal informa desfavorablemente y la encargada del Registro mediante auto deniega la autorización para celebrar el matrimonio proyectado.

De las declaraciones de las audiencias se deduce, [que no hay conocimiento sobre circunstancias personales importante acerca del otro contrayente, como fecha de nacimiento o conocer a sus respectivas familias. Además, ella declara que "casándose es más fácil conseguir los papeles, dada su situación irregular es España”]. 
c) Resolución de la DGRN de 20 de diciembre de 2013

Una mujer de nacionalidad española y un hombre de nacionalidad senegalesa, presentan ante el Registro Civil escrito para solicitar autorización para contraer matrimonio civil.

Se celebran las audiencias reservadas y el Ministerio Fiscal deduce que de las declaraciones de las audiencias se extrae que no hay un verdadero consentimiento matrimonial. El encargado del Registro resuelve denegando la autorización.

En la audiencia privada la promotora declara textualmente que, ["el hecho de que se quiere casar es para que él tenga los papeles y tenga la posibilidad de trabajar" y que "ella aunque se case seguirá viviendo en su actual domicilio", sin él. Además, existe un total desconocimiento de circunstancias personales del otro contrayente y que deberían ser conocidas debido a su relevancia].

d) Resolución de la DGRN 18 de enero de 2012

Una mujer de nacionalidad española junto con un hombre de nacionalidad marroquí, inician expediente en el Registro Civil, en solicitud de autorización para contraer matrimonio civil. Los interesados ratifican la solicitud y comparen dos testigos que alegan que no existe impedimento legal para que se celebre el enlace. Posteriormente se celebran las entrevistas en audiencia reservada, el Ministerio Fiscal se opone a la celebración del matrimonio. La encargada del Registro a la vista del contenido de las entrevistas decide resolver denegando la autorización.

De las audiencias se desprende que [existen numerosas contradicciones sobre elementos esenciales de la relación, que incompatibiliza con la declaración de la existencia de una vida común. Además él manifiesta que su motivo para contraer matrimonio es "para poder ir a sitios y tener los papeles"].

e) Resolución de la DGRN de 2 de septiembre de 2013

Un hombre de nacionalidad dominicana y una mujer con doble nacionalidad, dominicana y española, presentan en el Consulado General de España en Santo Domingo impreso de declaración de datos para la transcripción de su matrimonio civil celebrado con anterioridad. Oídos los interesados en audiencia privada, el encargado del Registro Civil Consular en Santo Domingo, dictó auto denegando la inscripción solicitada.

De las audiencias se desprende, [desconocimiento de circunstancias personales, que hacen difícil creer la existencia real de un matrimonio de 6 años de duración. Además él declara que en cuanto a proyectos futuros, que planean vivir en España y que ella lo condiciona a él para que le den los papeles, además planea trabajar en la construcción y se dice sabedor de que la inscripción del matrimonio le permitiría salir de su país y residir en España, comentando seguidamente que obtener un contrato de trabajo es más difícil].

f) Resolución de la DGRN de 5 de julio de 2013

Un hombre nacido en Cuba pero con nacionalidad española recuperada y una mujer de nacionalidad cubana, inician expediente en solicitud de autorización para contraer matrimonio civil ante el Registro Civil. Al celebrarse las entrevistas en audiencia reservada, el Ministerio Fiscal informa desfavorablemente y el encargado del Registro Civil dicta auto denegando la autorización.

En la audiencia, [la mujer declara que han decidido contraer matrimonio puesto que hace poco intentó resolver sus papeles y no lo consiguió, y que quieren estar organizados por cualquier cosa que pase]. 
Por otro lado, indicios tales como los siguientes, pueden probar la validez del matrimonio: la existencia de hijos comunes, o el hecho de que la mujer esté embarazada (Resoluciones de la DGRN, de 18 de enero de 1999, de 15 de junio de 1999, de 18 de octubre de 1999, de 13 de enero de 2000, o de 3 de julio de 2001), la residencia legal del contrayente extranjero en España o en cualquier otro país de la UE (Resolución de la DGRN, de 27 de septiembre de 2000 , y de 25 de octubre de 2000), el conocimiento de circunstancias personales y familiares del otro contrayente, las concordancias entre las declaraciones de ambos contrayentes, o la posibilidad de comunicación a través de una lengua común.

Además, deben considerarse intrascendentes circunstancias tales como que el contrayente extranjero se encuentre en prisión (Resolución de la DGRN, de 11 de enero de 2000), haberse conocido a través de Internet (Resolución de la DGRN, de 3 de marzo de 2000), tener preparada la documentación para el expediente matrimonial antes de que el contrayente extranjero venga a España y conozca al contrayente español (Resolución de la DGRN, de 3 de marzo de 2000), o el hecho de contraer matrimonio por poderes (Resolución de la DGRN, de 19 de octubre de 1998).

\section{REFLEXIONES FINALES}

Primera- "Matrimonios de conveniencia" = fenómeno que no cesa. Las instrucciones dadas por el Ministerio de Justicia al personal de los Registros Civiles para detectar estos "matrimonios de conveniencia" no dejan de ser medidas de sentido común, que difícilmente garantizan que disminuyan el número de estos matrimonios fraudulentos. Si el Juez Encargado del Registro Civil llega a la convicción de que los interesados están actuando en fraude a la ley, beneficiándose de las consecuencias legales del matrimonio, ante la falta de verdadero consentimiento matrimonial, dicho matrimonio será declarado nulo por simulación, y al extranjero, en cuestión, se le aplicará la sanción correspondiente, prevista en la legislación de extranjería.

Segunda- "Matrimonios de conveniencia" = necesidad de una reforma legal. El nuevo panorama en el que nos encontramos exige acometer algunas reformas, que permitan afrontar la nueva realidad de una forma global. Varios caminos se pueden vislumbrar: a) por un lado, acometer la reforma del "generoso" artículo 22 de nuestro CC, de forma que se amplíen los plazos de adquisición de la nacionalidad española por matrimonio, hasta que el ciudadano extranjero pruebe que está totalmente integrado en España (en sentido contrario pensó el legislador español, cuando acometió la reforma del artículo 22 del CC, a través de la Ley 36/2002, de 8 de octubre, de modificación del Código Civil, al pensar que la integración se produce más rápidamente si hay matrimonio, incluso aunque el cónyuge haya fallecido); y/o, b) por otro lado, acometer la reforma de la legislación de extranjería, de forma que para la concesión de una autorización de residencia/autorización de residencia y de trabajo no baste sólo con acreditar el matrimonio con un ciudadano nacional de un estado miembro de la UE, ampliándose los plazos para el ejercicio del derecho a la reagrupación familiar. 


\section{BIBLIOGRAFÍA}

ARTUCH IRIBERRI, E. (2003). "Matrimonios mixtos: diversidad cultural y Derecho internacional privado". En Derecho registral internacional. Homenaje a la memoria del Profesor Rafael Arroyo Montero. Madrid: Iprolex, pp. 199-222.

CALVO CARAVACA, A. L., y CARRASCOSA GONZÁlEZ, J. (2004). "Matrimonios de complacencia y Derecho internacional privado". En El Derecho de familia ante el siglo XXI: aspectos internacionales. Madrid: Colex, pp. 119-158.

CARRASCOSA GONZÁLEZ, J. (2002). "Matrimonios de conveniencia y nacionalidad española". En Anales de Derecho. Murcia: Universidad de Murcia, n 20 , pp. 7-34.

CREMADES GARCÍA, P. (2006). "Matrimonios de complacencia: una realidad". En Revista de la Facultad de Ciencias Sociales y Jurídicas de la Universidad Miguel Hernández, 1: 12-28, disponible en http://revistasocialesyjuridicas.umh.es.

DIAGO DIAGO, Mª P. (1996). "Matrimonios de conveniencia". En Actualidad Civil, no 2.

GARCÍA ZÚÑIGA, R. (2001). "Los Matrimonios de conveniencia como fraude de ley", disponible en http://www.porticolegal.com.

ORTEGA GIMÉNEZ, A. (coord.) (2011). Manual Práctico Orientativo de Derecho de la Nacionalidad. Barcelona: Difusión Jurídica y Temas de Actualidad.

ORTEGA GIMÉNEZ, A. (2008). "Matrimonios de conveniencia: por la nacionalidad española cualquier cosa". En Revista Economist \& Jurist. 118: 56-67

ORTEGA GIMÉNEZ, A. (2006). "Los matrimonios de conveniencia y el fútbol español". En ORTEGA GIMÉNEZ, A. y LÓPEZ ÁLVAREZ, A. (coords.). Cuestiones jurídicas actuales sobre el fútbol español. Barcelona: Bosch, pp. 47-75.

SALVADOR GUTIÉRREZ, S. (2004). "Registro Civil, inmigración y matrimonio". En Registro Civil: incidencia del fenómeno de la inmigración. Cuadernos de Derecho Judicial. Madrid: Consejo General del Poder Judicial, pp. 257-357.

SÁNCHEZ LORENZO, S. (2003). "La inconveniente doctrina de la DGRN acerca de los matrimonios de conveniencia", en Derecho registral internacional. Homenaje a la memoria del Profesor Rafael Arroyo Montero. Madrid: Iprolex, pp. 247-273.

\footnotetext{
Alfonso Ortega Giménez

Profesor de Derecho internacional privado en la Universidad Miguel Hernández de Elche; Subdirector Académico del Master en Comercio Internacional, organizado por la Universidad de Alicante. Es Director del Observatorio de la Inmigración de la ciudad de Elche y Vocal del Observatorio Valenciano de la Inmigración. Consultor de Derecho internacional privado de la Universitat Oberta de Catalunya (UOC). Además, es Consejero académico de PELLICER \& HEREDIA ABOGADOS y miembro del Consejo Asesor de la Revista Economist \& Jurist. Miembro de la Red Española de Política Social (REPS). Autor de diferentes artículos, notas, recensiones y comentarios publicados en Revistas científicas, técnicas y de divulgación, españolas y extranjeras; ha participado, como coordinador y/o autor, en más de 60 libros.
} 